\title{
Neuroimaging features of progressive ataxia and palatal tremor
}

\section{Achados de neuroimagem da ataxia progressiva com tremor palatal}

José Luiz Pedroso', Wladimir Bocca Vieira de Rezende Pinto', Paulo Victor Sgobbi de Souza', René Leandro Magalhães Rivero², Orlando Graziani Povoas Barsottini ${ }^{1}$

A 56-year-old man complained about a 6-year-history of gait disturbance and bilateral tinnitus. His neurological family history was unremarkable. Physical examination disclosed gait ataxia, slowly horizontal saccadic pursuit and a $2 \mathrm{~Hz}$ frequency palatal tremor. Neuroimaging unveiled inferior olivary complex hypertrophy bilaterally and mild cerebellar atrophy
(Figure), highly suggestive of progressive ataxia and palatal tremor (PAPT). PAPT represents a rare idiopathic neurodegenerative disease characterized mainly by progressive cerebellar ataxia, variable bulbar dysfunction and symptomatic palatal tremor ${ }^{1}$ with the peculiar neuroimaging finding of hypertrophy and variable hyperintensity of the inferior olivary complex ${ }^{2}$.
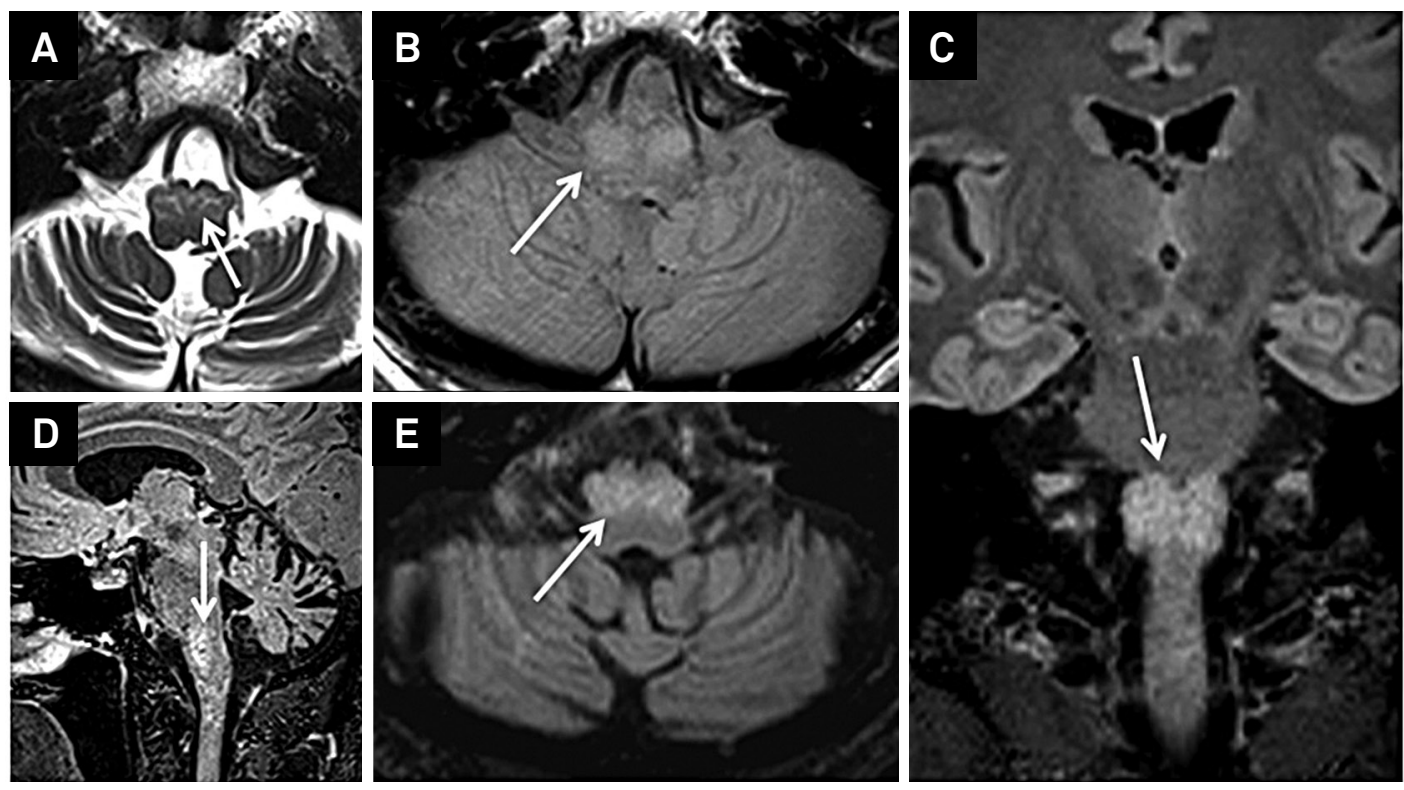

Figure. Different brain MRI sequences (A-E) showing cerebellar atrophy and bilateral hypertrophy with hyperintensities of the inferior olivary complex (white arrows), a frequently described finding in sporadic tremor ataxia and palatal tremor (PAPT).

1. Brinar VV, Barun B, Zadro I, Ozretic D, Habek M. Progressive ataxia and palatal tremor. Arch Neurol. 2008;65(9):1248-9. http://dx.doi.org/10.1001/archneur.65.9.1248
2. Samuel M, Torun N, Tuite PJ, Sharpe JA, Lang AE. Progressive ataxia and palatal tremor (PAPT): clinical and MRI assessment with review of palatal tremors. Brain. 2004;127(6):1252-68. http://dx.doi.org/10.1093/brain/awh137

\footnotetext{
'Universidade Federal de São Paulo, Unidade de Ataxia, Departamento de Neurologia e Neurocirurgia, Sao Paulo SP, Brazil; Universidade Federal de São Paulo, Departamento de Radiologia, Sao Paulo SP, Brazil.

Correspondence: Wladimir Bocca Vieira de Rezende Pinto; Departamento de Neurologia e Neurocirurgia, UNIFESP; Rua Pedro de Toledo, 650; 04023-900 São Paulo SP, Brasil. E-mail: wladimirbvrpinto@gmail.com

Conflict of interest: There is no conflict of interest to declare.

Received 05 July 2014; Received in final form 19 January 2015; Accepted 06 February 2015.
} 